\title{
Clinical and epidemiological spectrum of coronavirus disease 2019 in Central Kerala: a retrospective case series
}

\author{
Ronnie Thomas ${ }^{1 *}$, Bins M. John ${ }^{2}$, Joe Thomas Koothapally ${ }^{2}$, Sanjeev Kumar ${ }^{3}$, Supriya Adiody ${ }^{4}$, \\ Venu Balachandran ${ }^{2}$, Chithra Valsan ${ }^{5}$, Praveenlal Kuttichira ${ }^{6}$
}

\begin{abstract}
${ }^{1}$ Department of Community Medicine, Government Medical College, Kottayam, Kerala, India
${ }^{2}$ Department of General Medicine, ${ }^{3}$ Department of Paediatrics Medicine, ${ }^{4}$ Department of Pulmonology, ${ }^{5}$ Department of Microbiology, ${ }^{6}$ Principal, Jubilee Mission Hospital, Medical College and Research Institute, Thrissur, Kerala, India
\end{abstract}

Received: 04 January 2021

Revised: 08 February 2021

Accepted: 09 February 2021

\author{
*Correspondence: \\ Dr. Ronnie Thomas, \\ E-mail: ronpauloc@gmail.com
}

Copyright: (c) the author(s), publisher and licensee Medip Academy. This is an open-access article distributed under the terms of the Creative Commons Attribution Non-Commercial License, which permits unrestricted non-commercial use, distribution, and reproduction in any medium, provided the original work is properly cited.

\begin{abstract}
Kerala state in India was known for its early response to the Covid-19 pandemic by public health mitigation measures through science-based advocacy. The objective of this study was to analyze epidemiological and clinical characteristics of COVID-19 patients admitted to a tertiary care center in central Kerala. This retrospective case series was undertaken by reviewing the medical records and extracting the epidemiological data, clinical symptoms and laboratory findings of consecutive patients admitted between April $1^{\text {st }}$ and September 31, 2020. Clinical and demographic parameters of hospitalized patients were analyzed regarding their association with the severity of disease. The mean age of the patients was 35.8 years with significant male predominance. Shopkeepers represented $15.6 \%$ of the patients and healthcare workers represented $12.5 \%$. Primary contact with a known case was documented in $62.5 \%$ of the patients. Asymptomatic patients constituted $25 \%$ of the patients and the most commonly experienced symptoms were fever, cough, breathlessness and diarrhea. Three patients had atypical presentations in the form of generalized seizures, intussusception and generalized anxiety with suicidal ideation. Neutrophilia and Lymphopenia were the most dominant laboratory finding. The clinical spectrum of COVID-19 in the study population is wider than previously described in literature.
\end{abstract}

Keywords: COVID-19, Kerala, Clinical spectrum, Epidemiological profile, Case series

\section{INTRODUCTION}

Coronavirus disease 2019 (COVID-19) was declared a global pandemic by the World Health Organization (WHO) on 12 March 2020. ${ }^{1}$ As of October 2, 2020, the WHO reported a total of 34,495,176 confirmed cases of COVID-19 and 1,205,729 deaths caused by SARS-CoV-2 infections. The disease has spread to almost all the countries and has become a global pandemic.

COVID-19 has a wide range of clinical presentations. A good proportion of patients with COVID-19 did not have symptoms or radiologic abnormalities on initial presentation, which has made clinical diagnosis of the infection a challenge. ${ }^{2}$ The most frequently reported symptoms included cough, fever, myalgias, gastrointestinal symptoms, and anosmia. ${ }^{3}$ Initial studies showed a high incidence rate of respiratory failure and a fatality rate high as $5.5 \% .^{2}$ Published studies on the clinical characteristics of covid-19 shows varying manifestations depending on the demographic and social attributes of the population. The spread of the epidemic depends on the health system capacity and the ability to implement community mitigation measures. The socio- 
demographic distribution and clinico-epidemiological characteristics of COVID-19 in a Kerala, a state with a strong social foundation and efficient public health system may give insights on the epidemiology of COVID-19.

As the authors did the review of records in the initial phase of the pandemic all patients who tested positive were admitted even though they were not sufficiently ill to merit being hospitalized. Here, we describe the clinicoepidemiological profile of the first 32 consecutive patients with COVID-19 who were admitted to a tertiary care institution in Kerala, South India.

\section{CASE SERIES}

This retrospective case series includes subjects of all ages with confirmed COVID-19 who were consecutively admitted between April $1^{\text {st }}$ and September 31, 2020, at Jubilee Mission Medical College and Research Institute, a 1900 bedded referral centre in Thrissur district of Kerala. Cases were confirmed through closed system reversetranscriptase-polymerase-chain-reaction assays performed on nasopharyngeal swab specimens.

The authors reviewed the medical records and extracted the recent exposure history, travel history, clinical symptoms and laboratory findings on admission. Radiologic assessments including chest radiography and laboratory investigations like Liver function tests, renal function tests, inflammatory markers like d-dimer etc were performed according to the clinical severity of the patient's illness. For the purpose of analysis cases were divided into two groups namely the non-severe group (asymptomatic-mild) and the moderate/severe group. The qqualitative variables were expressed as proportions and quantitative variables were expressed as mean and standard deviations. The association between the severity of disease sand selected socio-demographic variables, were assessed using $t$ test and $\mathrm{X} 2$ test and $\mathrm{P}$ value $<0.05$ was considered to be statistically significant.

A total of 32 COVID-19 cases were detected in the Institution up to 30 September 2020. The mean age of the patients was 35.8 years and $62.5 \%$ (20) among them were males. The history of contact with a known case was documented in $20(62.5 \%)$ patients. Four of them $(12.5 \%)$ were health care workers and the major occupational group was found to be shopkeepers constituting $15.6 \%$ of the patients. Three patients $(9.37 \%)$ give a history of travel outside the state and were classified as imported cases. The rest 29 cases were locally acquired cases. Among them 9 were first-generation patients $(28.1 \%)$ and 11 were second-generation patients $(34.3 \%)$. In the remaining 9 patients $(28.1 \%)$, the source of infection could not be identified.

Most of the patients experienced only minor symptoms. The clinical categorisation of the patients was done at the time of admission based on the Kerala government protocol for assessing the severity of COVID-19. The patients were categorized as Asymptomatic, mild, moderate and severe. For Analytic purpose asymptomatic and mild disease were categorised as non-severe. Out of the total 32 patients, 8 patients $(25 \%)$ were asymptomatic throughout their course in the hospital. Other patients had mild symptoms. Majority of the patients (43.75) in the hospital had moderate symptoms. Only $6.25 \%$ of patients developed moderate symptoms and required ICU admission. One patient admitted in the ICU died and the mortality rate was $3.1 \%$. Patients with severe disease were older than those with non-severe disease and this was found to be statistically significant ( $p$ value $=0.011$ ). No significant difference was found between males and females with respect to the severity of disease.

Among the subjects who were symptomatic fever was the most dominant symptom $(54.2 \%)$ followed by cough (37.5\%) and breathlessness (37.5\%). A good proportion of patients $(25 \%)$ had gastrointestinal symptoms especially diarrhoea. This includes two pediatric patients who presented with diarrhea alone. Headache and myalgia were reported in $20.8 \%$ of the patients admitted. Anosmia and sore throat have been reported in $8.3 \%$ of the patients. One patient complained of ageusia. Three patients had atypical presentations at the time of diagnosis. A 34 years old previously healthy male presented with a single episode of generalized seizures. The second patient was an 18 years old female who presented with generalized anxiety and suicidal ideation. The third case was a one-year-old infant with intussusception.

Among the overall patients, $34.4 \%$ had at least one coexisting illness. Nine patients $(28.1 \%)$ had underlying co morbidity in the form of diabetes mellitus, $6(18.75 \%)$ had hypertension, 2 (6.25\%) each had coronary artery disease and chronic kidney disease. One patient had Alcoholic Liver disease. The patients also included an infant with Tuberous sclerosis and a 24 years old male with Fanconis Anemia. Both had moderate symptoms.

Table 1: Distributions of patients according to the disease severity.

\begin{tabular}{|lll|}
\hline Disease severity & $\begin{array}{ll}\text { All cases }(\mathbf{n = 3 2}) \\
\text { Frequency }\end{array}$ & $\begin{array}{l}\text { Proportion } \\
(\mathbf{\%})\end{array}$ \\
\hline Asymptomatic & 8 & 25 \\
\hline Mild symptoms & 8 & 25 \\
\hline Moderate symptoms & 14 & 43.75 \\
\hline Severe symptoms & 2 & 6.25 \\
\hline
\end{tabular}

The presence of any coexisting illness was significantly more common among patients with moderate or severe disease $(\mathrm{p}$ value $=0.009)$.

The most common laboratory abnormalities were raised neutrophil count, lymphopenia and increased levels of C- 
reactive protein. A total of 11 patients (34.4\%) had lymphopenia in their hemogram during the course of admission. 4 patients $(12.5 \%)$ had leucocytosis and 2 patients $(6.25 \%)$ presented with thrombocytopenia. Patients who were in the moderate to severe category were more likely to have elevated liver-function values than were patients who had non-severe disease. The 2 patients in the severe category had raised levels of inflammatory markers (CRP and D-dimer) and needed oxygen support.

Table 2: Frequency and proportion of reported symptoms among the patients.

\begin{tabular}{|lll|}
\hline \multirow{2}{*}{ Symptoms } & \multicolumn{2}{l|}{ Symptomatic cases $(\mathbf{n = 2 4})$} \\
\hline Fever & Frequency $\mathbf{( N )}$ & Proportion $\mathbf{( \% )}$ \\
\hline Cough & 13 & 54.2 \\
\hline Breathlessness & 9 & 37.5 \\
\hline Diarrhoea & 6 & 37.5 \\
\hline Myalgia & 5 & 25 \\
\hline Headache & 5 & 20.8 \\
\hline Rhinitis & 5 & 20.8 \\
\hline Fatigue & 4 & 20.8 \\
\hline Sore throat & 2 & 16.7 \\
\hline Anosmia & 2 & 8.3 \\
\hline
\end{tabular}

Table 3: Association of demographic factors and comorbid conditions with disease severity.

\begin{tabular}{|c|c|c|c|c|}
\hline \multicolumn{2}{|l|}{ Attribute } & $\begin{array}{l}\text { Mild } \\
\text { disease } \\
(n=16)\end{array}$ & $\begin{array}{l}\text { Moderate- } \\
\text { severe } \\
\text { disease } \\
(n=16)\end{array}$ & $\begin{array}{l}\mathbf{P} \\
\text { value }\end{array}$ \\
\hline \multicolumn{2}{|c|}{ Mean age (yrs) } & $\begin{array}{l}27.07 \pm \\
18.48\end{array}$ & $\begin{array}{l}44.29 \pm \\
17.12\end{array}$ & $0.011^{*}$ \\
\hline \multirow{2}{*}{ Gender } & Male & $8(50 \%)$ & $11(68.7 \%)$ & \multirow{2}{*}{0.280} \\
\hline & Female & $8(50 \%)$ & $5(31.3 \%)$ & \\
\hline \multirow{2}{*}{$\begin{array}{l}\text { Comorbid } \\
\text { conditions }\end{array}$} & Yes & $\begin{array}{l}2 \\
(12.5 \%)\end{array}$ & $9(56.3 \%)$ & \multirow{2}{*}{$0.009 *$} \\
\hline & No & $\begin{array}{l}14 \\
(87.5 \%)\end{array}$ & $7(43.7 \%)$ & \\
\hline
\end{tabular}

\section{DISCUSSION}

The present study has shown a significant male predominance and a predilection for middle aged individuals in COVID-19 incidence. This observation was found to be similar to a previous study from Kerala which reported that the infections reported were mainly among working-age men, with a travel history. ${ }^{4}$ However only 3 $(9.4 \%)$ patients in our cohort had a travel history. The findings from the present study underscore the need for strengthening preventive measures for healthcare workers and shopkeepers. ${ }^{5}$
The proportion of people with COVID-19 who remain completely asymptomatic has been a challenge to the public health mitigation measures during the pandemic. In the current study, $25 \%$ of the individuals reported no symptoms. The authors observed this pattern in the hospital at a time when the healthcare system was not yet overloaded and hospital capacity was at the highest in Kerala. This estimate is similar to previous estimates in literature as evidenced by a systematic review by Sirordia et al. ${ }^{6}$ Among the 32 patients with Covid-19 who were hospitalized in this tertiary care centre, the manifestations of the disease at presentation were generally similar to those in the initial case series from China. ${ }^{3}$ According to data from China, $81 \%$ of people with Covid-19 had mild or moderate disease and only $5 \%$ had critical illness. ${ }^{3}$ However, gastrointestinal symptoms appeared to be more common than reported elsewhere. All the paediatric cases in our study population presented with diarrhoea. This is in contrast to observations made in rest of the country. ${ }^{7}$ Anosmia was uncommon in our study population but published studies from Europe reports that the loss of smell as a key symptom of mild-to-moderate COVID-19 patients. $^{8}$

Three patients in our cohort had atypical presentations. A one-year-old infant who had preceding mild respiratory symptoms and tested positive for COVID-19, presented with intussusception. This clinical presentation was found to be in agreement with a case report from U. K. which highlights a similar association. ${ }^{9}$ The second patient was a 34 years old male patient presented with a single episode of generalized seizures. Literature reports occasional seizures in COVID-19 patients and it is hypothesized that different pathophysiological mechanisms like hypoxemia and cytokine storm associated with COVID-19 may theoretically lower seizure thresholds. ${ }^{10}$ The third atypical presentation was that of a 1-year-old female who was a student presenting with severe anxiety and suicidal ideation. According to a published report from the United States, the prevalence of symptoms of anxiety disorder was approximately three times and prevalence of depressive disorder was approximately four times that reported in the previous year. ${ }^{11}$ In the same study twice as many respondents reported serious consideration of suicide as compared to the previous year data. ${ }^{11}$

Recent epidemiological research has shown that comorbidities were present in nearly half of patients with moderate to severe COVID-19, with hypertension being the most common comorbidity, followed by diabetes and coronary heart diseases. ${ }^{12}$ The higher incidence of severe COVID-19 among obese individuals is attributed to the altered pulmonary physiology and increased ACE2 expression associated with obesity. ${ }^{13}$ The derangements in innate and adaptive immunity, aggravation of inflammatory storm and microangiopathy seen in Diabetic patients contributes to severe disease. ${ }^{13}$ In the current study obesity, diabetes and hypertension were found to be common to both the patients who required 
ICU admission and may be considered as risk factors for respiratory failure leading to invasive mechanical ventilation. An ICU admission rate of $6.2 \%$ in this study is lower compared to previous large reports from Wuhan and the New York area (14.2\%). ${ }^{14}$

In terms of laboratory tests, the absolute value of lymphocytes in $34.4 \%$ of our patients were reduced. This result is consistent with published literature and suggests that COVID-19 infection is similar to other respiratory virus infections in causing depletion of lymphocytes. ${ }^{15,16}$ Previous reports showed that a proportion of COVID-19 patients had differing degrees of liver function abnormality. This report is consistent with our findings. Two patients in the moderate to severe category had thrombocytopenia. This is in agreement with a pooled analysis in a meta-analysis which revealed that platelet count was significantly lower in patients with more severe COVID-19. ${ }^{17}$ As reported elsewhere higher CRP levels were observed in the moderate to severe group which, which corresponds with the increased inflammatory response. ${ }^{18}$

\section{CONCLUSION}

This case series describes the clinical spectrum of COVID-19 in Thrissur district of Kerala. COVID-19 infection in the population exhibited a wide wide range of symptoms with a substantial proportion of asymptomatic patients. The most commonly experienced symptoms of COVID-19 were fever, cough, breathlessness and diarrhea. The study underscores the importance of raising the awareness of primary care physicians and field level healthcare workers about the wide spectrum of COVID19 clinical presentation.

Funding: No funding sources

Conflict of interest: None declared

Ethical approval: Not required

\section{REFERENCES}

1. Coronavirus disease 2019 (COVID-19) was declared a global pandemic by the World Health Organization (WHO) on 12 March 2020.

2. Zhu J, Ji P, Pang J, Zhong Z, Li H, He C, et al. Clinical characteristics of 3,062 COVID-19 patients: a meta-analysis. J Med Virology. 2020.

3. Guan WJ, Ni ZY, Hu Y, Liang WH, Ou CQ, He JX, et al. Clinical characteristics of coronavirus disease 2019 in China. New England J Med. 2020;382(18):1708-20.

4. Ulahannan JP, Narayanan N, Thalhath N, Prabhakaran P, Chaliyeduth S, Suresh SP, et al. Collective for Open Data Distribution-Keralam (CODD-K) consortium. A citizen science initiative for open data and visualization of COVID-19 outbreak in Kerala, India. J Am Med Inform Assoc. 2020;27(12):1913-20.
5. Valsan N, Thomas R, Kuttichira P, Valsan C, James A. Willingness and psychological preparedness to attend to COVID-19 patients among healthcare workers in a tertiary care private hospital in KeralaA mixed method study. Kerala J Psychiatry. 2020.

6. Siordia JA. Epidemiology and clinical features of COVID-19: A review of current literature. J Clinical Virology. 2020.

7. Sarangi B, Reddy VS, Oswal JS, Malshe N, Patil A, Chakraborty M, et al. Epidemiological and clinical characteristics of COVID-19 in Indian children in the initial phase of the pandemic. Indian pediatrics. 2020;57(10):914-7.

8. Lechien JR, Chiesa-Estomba CM, Place S, Van Laethem Y, Cabaraux P, Mat Q, et al. Clinical and epidemiological characteristics of 1,420 European patients with mild-to-moderate coronavirus disease 2019. J Internal Med. 2020.

9. Makrinioti H, MacDonald A, Lu X, Wallace S, Jobson $\mathrm{M}$, Zhang $\mathrm{F}$, et al. Intussusception in 2 children with severe acute respiratory syndrome coronavirus-2 infection. J Pediatric Infectious Diseases Society. 2020;9(4):504-6.

10. Vohora D, Jain S, Tripathi M, Potschka H. COVID19 and seizures: Is there a link? Epilepsia. 2020;61(9):1840-53.

11. Czeisler ME, Lane RI, Petrosky E, Wiley JF, Christensen A, Njai R, et al. Mental health, substance use, and suicidal ideation during the COVID-19 pandemic United States, June 24-30, 2020. Morbidity and Mortality Weekly Report. 2020;69(32):1049.

12. Wang B, Li R, Lu Z, Huang Y. Does comorbidity increase the risk of patients with COVID-19: evidence from meta-analysis. Aging. 2020;12.

13. Zhou Y, Chi J, Lv W, Wang Y. Obesity and diabetes as high-risk factors for severe coronavirus disease 2019 (Covid-19). Diabetes/Metabolism Research Reviews. 2020:e3377.

14. Richardson S, Hirsch JS, Narasimhan M, Crawford JM, McGinn T, Davidson KW, et al. Presenting characteristics, comorbidities, and outcomes among 5700 patients hospitalized with COVID-19 in the New York City area. JAMA. 2020.

15. Henry BM, Cheruiyot I, Vikse J, Mutua V, Kipkorir V, Benoit J, et al. Lymphopenia and neutrophilia at admission predicts severity and mortality in patients with COVID-19: a meta-analysis. Acta Bio Medica: Atenei Parmensis. 2020;91(3):e2020008.

16. Rodriguez-Morales AJ, Cardona-Ospina JA, Gutiérrez-Ocampo E, Villamizar-Peña R, HolguinRivera Y, Escalera-Antezana JP, et al. Clinical, laboratory and imaging features of COVID-19: A systematic review and meta-analysis. Travel Med Infect Dis. 2020:101623.

17. Lippi G, Plebani M, Henry BM. Thrombocytopenia is associated with severe coronavirus disease 2019 (COVID-19) infections: a meta-analysis. Clinica Chimica Acta. 2020. 
18. Vial MR, Peters A, Pérez I, Spencer-Sandino M, Barbé M, Porte L, et al. COVID-19 in South America: clinical and epidemiological characteristics among 381 patients during the early phase of the pandemic in Santiago, Chile. BMC Infect Dis. 2020;20(1):1-8.
Cite this article as: Thomas R, John BM,

Koothapally JT, Kumar S, Adiody S, Balachandran $\mathrm{V}$, et al. Clinical and epidemiological spectrum of coronavirus disease 2019 in Central Kerala: a retrospective case series. Int J Community Med Public Health 2021;8:1503-7. 